\title{
Interdisciplinary and Transdisciplinary Research and Education in Canada: A Review and Suggested Framework
}

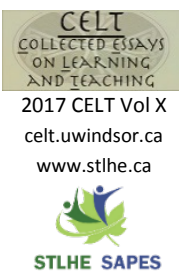

STLHE SAPES
Daniel Gillis, Jessica Nelson, Brianna Driscoll, Kelly Hodgins, Evan Fraser
\& Shoshanah Jacobs

University of Guelph

DOI: $10.22329 /$ celt.v10i0.4745

Transcending disciplinary boundaries is becoming increasingly important for devising solutions to the world's most pressing issues, such as climate change and food insecurity. Institutions of higher education often present challenges to teaching students how to work and innovate on transdisciplinary teams. We first define transdisciplinarity and like concepts, using these to review databases of three major funding agencies (CIHR, NSERC, and SSHRC) for awards given to interand transdisciplinary programs across ten fiscal years beginning 2005-2006 and ending 2014-2015 to identify trends in funding as an indicator of skill need. We then search for programs offering transdisciplinary learning opportunities at Canadian universities accounting for $71 \%$ of all students. Though the proportion of interdisciplinary and transdisciplinary funded research grants has risen considerably, we found only a few examples of interdisciplinary learning opportunities for students in post-secondary education programs. Generally, while students were able to take a range of courses, instruction remained discipline-specific. Specifically, Canadian undergraduates lack an in-program, experiential, transdisciplinary learning opportunity. We propose a framework (ICON) as a solution to fill this gap. Using senior independent study courses, which often have built-in curricular flexibility, students can participate with ICON while still obtaining credit towards their degrees. We conclude that transdisciplinary education opportunities are an essential part of the undergraduate experience and should be recognized across degree programs.

Aifty years ago, the most celebrated minds of bionic
technology gathered to discuss their research. Otto H. Schmitt, instead, presented a paper on the challenges that the field faced. Of top priority was to teach people to think across transdisciplinary lines. He suggested that the way to solve this problem in academia was by facilitating the meeting of researchers in diverse areas to avoid the "splintering into innumerable special groups" (Schmitt, 1960, p. 484). Little has changed since Schmitt's initial recommendation. There still remains a wellestablished need to eliminate disciplinary borders both in academic and professional settings.
Specifically, within the academic framework, our ability to solve problems through the generation of knowledge has traditionally been addressed from discipline-specific points of view. However, it has become apparent that the research needed to address today's complex problems requires the expertise of multiple disciplines (Choi \& Pak, 2006; Hagoel \& Kalekin-Fisherman, 2002). Cross-boundary complementary research and educational programs that are transdisciplinary in nature are necessary for our continued generation of knowledge. To encourage and build the skills that are necessary for transdisciplinarity to become more prominent in 
academic thinking, we should introduce the concept and begin practicing it during students postsecondary education.

Yet, upon entrance into post-secondary studies, students are splintered into groups. The selection and dispersion into respective majors is facilitated by a calendar of required courses and/or electives that produce disciplinary knowledge experts. In doing so, post-educational institutions foster discipline-specific thinkers. Yet, as Kolb and Kolb (2005) state, learning requires "facing and embracing differences," including those that exist between various banks of knowledge (p. 207). As a result, for today's students to be successful, they now require both discipline-specific knowledge and additional skills, including, but not limited to, effective communication, leadership, and teamwork (Hubball et al., 2010). Research by Tourse and colleagues (2008) supports the use of transdisciplinary education as a means to respond to this demand. As evidenced by their study, they concluded that by teaching transdisciplinary skillsets, students were able to approach tasks/challenges with a broader lens, could communicate and collaborate more effectively, and were more reflective when problem-solving towards a shared vision. Accordingly, while transdisciplinary programs in academia are not without challenges, the potential benefits are necessary for moving into a $21^{\text {st }}$ century approach to teaching and learning.

Further, it is important to add that transdisciplinary thinking and practices are not contradictory to disciplinary activities; rather, they complement and even extend disciplinary understanding. McGregor and Donnelly (2014) argue that the collaborative nature required for transdisciplinarity goes beyond institutions and into the larger global community, and fosters reconciliation between "all sciences and civil society," inviting a more holistic perspective (p. 165). Without transdisciplinary interactions, some disciplinary research may not ever have been considered (Rosenfield, 1992). By bringing together experts from a range of disciplinary backgrounds, including both students and researchers, broader social problems can be addressed thereby fostering a deeper and more extensive analysis (Rosenfield, 1992; Roux, Stirzaker, Breen, Lefroy \& Cresswell, 2010; Tourse et al. 2008).
By bringing together individuals from varying fields, there is an increase in potential opportunities to strengthen team building, communication skills, and mentoring, all of which are less likely to occur under traditional discipline-specific research and educational conditions (Roux et al., 2010).

Despite the priority for transdisciplinary collaboration, academia itself can act as a barrier because faculty members are often loyal to their discipline (Hagoel \& Kalekin-Fisherman, 2002). In this way, students are often not exposed to other ways of thinking and lack opportunities to broaden their skillsets through experiential and transdisciplinary learning. Breaking down disciplinary barriers is essential to promote transdisciplinary training. This must be acknowledged by faculty and administration to ensure the success of any cross-disciplinary higher level experiential learning approach to curriculum (Kolb \& Kolb, 2005). We need to teach students how to foster skills that promote collaborative thinking outside traditional disciplinary silos.

To demonstrate the need for transdisciplinarity, both in research and education, we turn to the study of bibliometrics. Bibliometrics is defined as the "organization, classification and quantitative evaluation of publication patterns...by mathematical and statistical calculus" (Sengupta, 1985 , p. 168). In this way, areas of research can be classified according to the amount of funding provided and the quantity of subsequent publications that result. We seek, not to quantify the output of inter- and transdisciplinary publications as an indicator of the need for multidisciplinary projects, but rather to consider only whether trends in funding to these kinds of projects exist. In part, we are utilizing data that may have bibliometric significance, but propose an alternate view of what this relationship might suggest about research need. Should there be an increase in funds allocated to inter-and transdisciplinary projects, it is arguable that Schmitt's 1960 proposal is being realized. As such, higher education has a responsibility to prepare students to meet this need.

In this paper, we present (a) whether there are trends in funding allocation to inter- and transdisciplinary programs, (b) if there are programs available to students, particularly undergraduates, to 
prepare them for entering an inter- or transdisciplinary job market, and (c) the presentation of an educational framework that responds to the growing need for transdisciplinary education in the undergraduate curriculum.

\section{Theoretical Framework}

Currently, data about funding are used in the study of bibliometrics to determine the relationship between funding and its respective publication results. However, trends in funding signal another question about which programs get funding and why. A 2009 article by Singh, Illes, Lazzeroni and Hallmayer proposes that media and societal pressure are some of the driving factors that steer funding allocation in specific directions. Their study considered recent increases in funds awarded to autism research in the United States and how demand for increased understanding led to a subsequent increase in the funding autism research projects received. Thus, demand for research becomes the acknowledgment of an area of research need.

Another example is the need for outreach programs that encourage women to pursue careers and education in science, technology, engineering, and mathematics (STEM); fields that are still largely comprised of men. Social stereotypes, pay-rate inequality, job demands, and overall career success, rather than poor academic achievement, suggest the need to change the way we view career options in STEM fields for women (Hango 2013; Stauffer 2015). It is not ability holding women back from these careers, but rather traditional limitations. Fostering programs that aim to transcend some of these long-held setbacks is a goal shared by high schools, second career programs, and within the higher education sector. Certainly, funding to these programs is also based on demand.

Today, funding allocation is not taken for granted. As Abramo, D'Angelo and Caprasecca (2009) present, there are pressures upon governments (and other funding organizations) as a result of demand for both fundamental and applied science. As such, an increase in awards given to inter- and transdisciplinary projects would be indicative of a societal need to pursue innovative efforts that encompass the needs driven by this demand.

\section{Defining Terms}

To investigate the prevalence and nature of existing transdisciplinary education programs, it is first important and necessary to define the term transdisciplinary as it shall be understood in this essay, and how it differs from the terms intradisciplinary, multidisciplinary, and interdisciplinary.

Intradisciplinary projects are those that involve knowledge builders from more than one subdiscipline within a larger parent discipline (Schary \& Cardinal, 2015). Here we use the term knowledge builder to purposefully capture the diversity of research systems available to discipline building beyond the western science paradigm (e.g. local and/or indigenous traditional knowledge). In an intradisciplinary setting, knowledge builders from subdisciplines within a larger parent discipline work together to solve problems using the tools, methods, and training that are contained within the entire domain of the discipline. Efforts to synthesize findings that benefit the entire discipline and progress the field through the addition of new knowledge is the result of such collaborations (Schary \& Cardinal 2015). Intradisciplinary endeavors are perhaps the least daunting form of disciplinary collaboration because each member of the team understands the basic lexicon of the domain, reducing potential issues with knowledge translation and transfer (KTT), and knowledge mobilization (KM).

Multidisciplinary teams can be thought of as a collection of intradisciplinary teams that are working towards a common goal but do not actively engage in the process of knowledge building among each other (Rosenfield, 1992). There is no specific KTT or KM between groups.

Interdisciplinary programs involve the collaboration of knowledge builders from two or more disciplines (Aboelela et al., 2007; Schary \& Cardinal, 2015; Rosenfield, 1992). In its simplest form, knowledge builders in one discipline identify that a solution to their discipline-specific problem requires the tools and methods of another domain to 
solve. As suggested by Schary and Cardinal (2015), this leads to the synthesis of results across disciplines, utilizing methods beyond only one discipline. Accordingly, in order to facilitate collaboration, there must also be a common lexicon that can be shared and understood by all members. To achieve this, it is necessary to ensure that all knowledge builders understand the challenge to be solved and how each will contribute to the solution. That is, KTT and KM become more relevant in interdisciplinary projects. On the other hand, Rosenfield (1992) suggests that the results reported following interdisciplinary projects are usually sequential and confined to respective disciplines, creating a division of knowledge. Nevertheless, outcomes often lead to the growth of both domains through the discovery of new knowledge or sharing of methods (Aboelela et al., 2007; Committee on Facilitating Interdisciplinary Research, National Academy of Sciences, National Academy of Engineering, Institute of Medicine, 2005; Grey \& Connolly, 2008).

Transdisciplinary research differs in that knowledge builders from two or more disciplines come together to develop new and participatory methods for creating solutions to a challenge that seemingly appears to fall within each domain (Pohl \& Hadorn, 2007; Wilcox \& Kueffer, 2008). They work together to transcend their disciplines, to develop a space for viewing a problem in a completely new way (Aboelela et al., 2007; Wilcox \& Kueffer, 2008). Clearly, skills in KTT and KM are necessary for a transdisciplinary team to be successful.

\section{Teaching Transdisciplinarity in Higher Education}

As Schmitt queried in 1960, how does one create a space for knowledge builders to develop a transdisciplinary solution that transcends the disciplines involved? Further, given the need to address pressing transdisciplinary problems such as climate change, food insecurity, and public health, how do we embed experiential learning opportunities within a transdisciplinary setting in higher education that benefits a spectrum of current and future knowledge builders (e.g., students, faculty, and community experts)?

In this article, we explore these questions by reviewing the current state of transdisciplinary research and educational efforts in Canadian universities. For all of these programs, we catalogued details such as project focus, actors engaged (funding agencies, community partners, students, researchers), level of transdisciplinarity, KTT or KM likelihood, and techniques used (scholarships, experiential learning, research application). We included a characterization of the level of transdisciplinarity based on the concepts of intra-, multi-, inter-, and transdisciplinary research as described previously, and we note that programs that have been self-identified as transdisciplinary may be characterized in other ways here. Finally, we propose a framework for transdisciplinary education in institutes of higher learning at the senior undergraduate level, one that requires minimal restructuring.

\section{Methods}

To describe the current state of transdisciplinary efforts in institutes of higher education in Canada, data were collected in two ways. First, we queried the three major funding agencies in Canada to identify the prevalence of transdisciplinary programs at the research level, and an indication of HQP (highly qualified personnel) training occurring in a transdisciplinary setting. Second, we systematically reviewed the available academic literature and Canadian university web pages to identify existing transdisciplinary programs across the country.

\section{Tri-Council Funding}

Each of the three major funding agencies in Canada, the Natural Sciences and Engineering Research Council (NSERC) (http://www.nserccrsng.gc.ca/ase-oro/index_eng.asp), the Canadian Institutes of Health Research (CIHR) (http://webapps.cihrirsc.gc.ca/funding/\%20Search?p _language=E\&p_version=CIHR), and the Social Sciences and Humanities Research Council (SSHRC) 
(http://www.outil.ost.uqam.ca/CRSH/RechProj.asp $\mathrm{x}$ ? vLangue $=$ Anglais), provide an online database of successfully funded grants that include the grantee, their institution, the grant type, the amount awarded, and the year(s) of the award. These data were filtered by keyword using the search terms interdisciplinary, inter-disciplinary, transdisciplinary, and transdisciplinary, and exported to Microsoft Excel. Data were aggregated to determine the number of yearly payments to successfully funded grants, and total dollars awarded by each tri-council agency for each year, and for each year and search term. Data with matching keywords of inter-disciplinary and interdisciplinary were treated as the same, and likewise for trans-disciplinary and transdisciplinary. Other than noting 1) an inflation rate of approximately $15 \%$ between 2006 and $2015^{1}$ (Bank of Canada, n.d.), and 2) a $7 \%$ reduction in after-inflation tri-council funding overall since $2007^{2}$ (Statistics Canada, 2016), we have ignored the effects of inflation for our comparison.

\section{Canadian programs}

To understand the scope of transdisciplinary programs in universities across Canada, we searched the peer-reviewed literature (via Google Scholar, PRIMO, and Web of Science) for articles matching the search terms/phrases transdisciplinary/interdisciplinary + research/program/project + Canada/Canadian + university/universities. We also obtained a list of 96 Canadian universities from the Universities Canada website, ${ }^{3}$ and filtered this list to include only those schools with more than 15,000 full- or part-time undergraduate students based on 2015 enrolment numbers. Of 96 Canadian universities, 26 were selected, representing slightly more than $71 \%$ of all
Canadian students enrolled either full- or part-time at the undergraduate or graduate level (Table 1).

Each of the Canadian university websites included in the filtered list was searched using the terms transdisciplinary and interdisciplinary. Programs discovered through our research were considered for this review if they were active at some point during the period 2006-2015, and if they self-identified as transdisciplinary or interdisciplinary.

We evaluated each program using a scale of transdisciplinarity as described by Jacobs, Nicol, and Helms (2014) to categorize programs as having low, medium, or high transdisciplinarity. Programs on the lower end of this spectrum represent some limited form of transdisciplinarity wherein only 2 or 3 related fields have worked in cooperation on a project. Programs at the high end of the scale represent efforts where a large number and variety of disciplines have worked together on a project. Those programs that rank in the medium level of transdisciplinarity represent either more diversity in the disciplines collaborating, or in a greater number of fields being represented than those that rank on the low end of the spectrum, but do not have enough of these qualities to qualify as high on the transdisciplinary scale. Programs were then listed, reviewed, and evaluated (where possible) based on (a) level of transdisciplinarity (low/medium/high); (b) project prospects (whether it was available to undergraduates, graduates or researchers); (c) funding source; (d) whether or not there was a community partner; (e) whether the efforts are likely to foster KTT or KM (based on level of transdisciplinarity as it relates intrainter- multi- and transdisciplinary as defined above); and ( $f$ ) additional techniques used (e.g. community engaged scholarships, experiential learning).

\footnotetext{
${ }^{1}$ Inflation rate was determined by inputting the date rate (2006-2015) into the appropriate boxes in the calculator section of the website. Percent change is equivalent to the inflation rate.

2 To determine the percent reduction in after-inflation tri-council funding, we went to the website and changed the date rate to reflect 2007 values up until 2015, and only selected the 3 desired federal agencies.

32015 full-time and part-time fall enrolment at Canadian universities (http://www.univcan.ca/universisties/facts-andstats/enrolment-by-university/), last checked March, 2016.
} 


\section{Table 1}

Full-time (FT) and part-time (PT) students enrolled in undergraduate (UG) or graduate (G) degrees in all public Canadian universities, and in public Canadian universities with FT+PT UG enrollment exceeding 15,000 students. ${ }^{*}$

\begin{tabular}{|c|c|c|c|c|}
\hline & FT UG & FT G & PT UG & PT G \\
\hline \multirow[b]{2}{*}{$\begin{array}{r}\text { Number Students (Canadian universities }>15,000 \text { FT }+ \text { PT } \\
\text { undergraduates) }\end{array}$} & 865,065 & 157,146 & 237,317 & 52,846 \\
\hline & 606,850 & 123,750 & 163,220 & 33,050 \\
\hline Percent of students covered by this study ${ }^{\dagger}$ & 70 & 79 & 69 & 63 \\
\hline \multicolumn{5}{|c|}{$\begin{array}{l}\text { *Universities with enrolment over } 15,000 \text { included: Athabasca University, University of Alberta, University of } \\
\text { Calgary, The University of British Columbia, Simon Fraser University, University of Victoria, University of } \\
\text { Manitoba, Dalhousie University, Brock University, Carleton University, McMaster University, Queen's University, } \\
\text { Ryerson University, University of Waterloo, University of Guelph, University of Ottawa, University of Toronto, } \\
\text { University of Western Ontario, Wilfrid Laurier University, York University, Concordia University, McGill } \\
\text { University, Université Laval, Université de Montréal, Université du Québec à Montréal, and the University of } \\
\text { Saskatchewan. }\end{array}$} \\
\hline
\end{tabular}

\section{Results}

\section{Transdisciplinary Research in Canada}

\section{Tri-Council Funding}

A total of 4,467 records matching the keyword search were extracted and downloaded from the online tricouncil funding results databases spanning the 10 fiscal years 2005-2006, through 2014-2015. Each record represented a single annual payment to a successful award. As such, a multi-year research program would be represented in each year in which it was paid. The records represented over $\$ 427.2$ million in funding, of which $\$ 10.2, \$ 86.5$, and $\$ 4.8$ million were self-identified as transdisciplinary within the NSERC, CIHR, or SSHRC databases, respectively. These values represent $0.10 \%, 1.01 \%$, and $0.07 \%$ of the total funding awarded by each of the tri-council agencies during this same period.

To understand trends in interdisciplinary and transdisciplinary funding by the tri-council agencies, data were aggregated and compared for the time periods with the fiscal year ending in 2006-
2010, and 2011-2015. The two periods are compared using a per-year average. Summary data are provided in Table 2.

Overall, the annual number of interdisciplinary and transdisciplinary awards paid per year have increased approximately 55\% between the two periods, with annual funding up $45 \%$. This far out-paces the $7 \%$ increase in total funding paid across all tri-council agencies for all awards between these two periods. This is not a consistent trend between the two labels as the number of awards paid per year for self-identified transdisciplinary grants are down approximately $10 \%$, with total funding down approximately $10 \%$, with total funding down slightly more than $2 \%$. Further, these trends are not consistent within the tri-council funding agencies.

Of the tri-council funding agencies, NSERC has seen the most significant changes to the number of awards paid per year, and in total funding awarded to programs labeled interdisciplinary or transdisciplinary. Specifically, the yearly number of award payments made and total funding have increased more than 3 times for research programs labeled as either interdisciplinary or transdisciplinary between the period 2006-2010, and 2011-2015. The 


\section{Table 2}

A summary of self-identified interdisciplinary (I) and transdisciplinary (T) funded research awards and funding per year, by tri-council funding agency, paid during periods with the fiscal year ending 2006 through 2010, and 2011 through $2015^{\ddagger}$.

\begin{tabular}{|c|c|c|c|c|c|}
\hline $\begin{array}{l}\text { Funding } \\
\text { Agency }\end{array}$ & Period & $\begin{array}{l}\text { Number of } \\
\text { Grants Paid } \\
\text { Per Year (T) }\end{array}$ & $\begin{array}{l}\text { Number of } \\
\text { Grants Paid Per } \\
\text { Year (I+T) }\end{array}$ & $\begin{array}{c}\text { Funding Paid Per } \\
\text { Year ( } \mathrm{T} \text { in } \\
\text { \$millions) }\end{array}$ & $\begin{array}{c}\text { Funding Paid Per } \\
\text { Year (I + T in } \\
\text { \$millions) }\end{array}$ \\
\hline \multirow[t]{2}{*}{ NSERC } & $2006-2010$ & 2.80 & 85.40 & $\$ 0.29$ & $\$ 6.26$ \\
\hline & $2011-2015$ & 9.00 & 264.20 & $\$ 1.76$ & $\$ 21.26$ \\
\hline \multirow[t]{2}{*}{ CIHR } & $2006-2010$ & 46.00 & 165.80 & $\$ 9.54$ & $\$ 24.46$ \\
\hline & $2011-2015$ & 32.00 & 169.20 & $\$ 7.77$ & $\$ 24.37$ \\
\hline \multirow[t]{2}{*}{ SSHRC } & $2006-2010$ & 3.20 & 98.80 & $\$ 0.44$ & $\$ 4.10$ \\
\hline & $2011-2015$ & 6.00 & 110.00 & $\$ 0.52$ & $\$ 4.98$ \\
\hline
\end{tabular}

\footnotetext{
${ }^{\ddagger}$ An award that spans multiple years will contribute to the yearly count of awards, and the total funding paid for each
} year the award is active.

change is even more dramatic when considering that NSERC paid 3 times more transdisciplinary grants in the period 2011-2015 than in the period prior, but total funding paid out increased 6-fold. Moreover, the average annual payments for transdisciplinary awards increased $86 \%$ from approximately $\$ 105,000$ in the 2006-2010 period, to $\$ 195,000$ in the 2011 2015 period. This compares to only a $12 \%$ increase in average annual payments for all NSERC awards paid out between the two periods. Finally, transdisciplinary funding increased from $0.03 \%$ to $0.17 \%$ of the total funding awarded by NSERC between 2006-2010, and 2011-2015. These changes are likely a result of the introduction of granting programs (e.g. NSERC CREATE, and NSERC Strategic Partnerships) with an interdisciplinary or transdisciplinary collaboration focus.

Between 2006-2010 and 2011-2015, CIHR saw a $2 \%$ increase in the number of awards paid (with funding decreasing by slightly less than $1 \%$ ) to interdisciplinary and transdisciplinary programs. The annual number of awards paid to self-identified transdisciplinary grants in the most recent period dropped to $70 \%$ (and annual funding to only $81 \%$ ) of the previous 5 years. Average annual payments to transdisciplinary awards increased $17 \%$ from slightly more than $\$ 207,000$ to approximately $\$ 242,000$ - on par with the $16 \%$ increase in average annual payments made to all CIHR awards. It should also be noted that funding to transdisciplinary awards decreased from $1.13 \%$ to $0.90 \%$ of all CIHR awards between the two periods.

Similar to NSERC, SSHRC has increased annual funding for self-identified interdisciplinary and transdisciplinary programs. In the most recent five-year period, the number of payments to interdisciplinary and transdisciplinary awards increased by approximately $11 \%$ between periods, and average annual funding paid to transdisciplinary awards decreased 37\%, from approximately 
$\$ 137,850$ to $\$ 86,700$. Total funding to transdisciplinary awards stayed relatively stable at $0.07 \%$ and $0.08 \%$ of the total funding awarded by SSHRC during these two periods.

\section{Transdisciplinary Education in Canadian Universities}

A review of the literature and of Canadian university websites identified numerous undergraduate or graduate courses, degree programs, research groups, faculties, or institutions that self-identified as being interdisciplinary or transdisciplinary in nature. Of the universities surveyed, a vast majority offer interdisciplinary degree programs at the undergraduate or graduate level. Several universities also offer certificates in interdisciplinary studies, including Dalhousie, Simon Fraser, and Ryerson, with the bulk of these focused in the domains of health and medicine. There were no undergraduate or graduate degree programs, or certificate programs found that identified as being transdisciplinary in nature, save for a graduate degree in biophotonics offered at Université de Laval. In the following sections, we summarize some of the findings at the undergraduate and graduate level, highlighting relevant resources and specific programs. For a more detailed list of transdisciplinary programs, please refer to Appendix A.

\section{Undergraduate programs}

Undergraduate programs labeled as interdisciplinary were found to vary across Canada and within institutions. They include minors, stream-based coursework, and formal degrees in interdisciplinary studies that span the physical and engineering sciences, arts, social sciences and humanities, and health sciences domains, with a goal of teaching students the skills and methods of two or more disciplines. Several of the interdisciplinary programs reviewed appear to be contained within a single broad domain (such as the University of Alberta's Peace and Post Conflict Studies Certificate, or the University of Guelph's Interdisciplinary Physical Science program), while others combine studies from two or three domains (e.g., Carleton's Bachelor of Health Sciences program, or Dalhousie's Interdisciplinary Health Studies Certificate program). Despite this, the undergraduate programs appeared to lack a specific space for an interdisciplinary (or transdisciplinary) classroom to truly take shape. That is, if a university offers an interdisciplinary undergraduate program spanning disciplines $\mathrm{X}$ and $\mathrm{Y}$, students are usually required to learn about each discipline through separate siloed courses. Several exceptions include the University of Alberta's InSciTE program, and the University of Guelph's Interdisciplinary Physical Sciences program. In the former case, students study a life sciences or physical sciences stream, with three prescribed siloed courses (e.g., Biology, Math, Chemistry), and a two-semester project course with a focus on data analysis and the scientific method. In the latter, students forgo siloed mathematics and physics courses and instead take two-semester long courses that combine the pedagogical outcomes required for studying physics and math.

We could not find any specific evidence that universities are presently offering a regular for-credit course that teaches students skills for working in an interdisciplinary or transdisciplinary setting at the undergraduate level. This is not to say that interdisciplinary and transdisciplinary courses do not exist, but that most of the undergraduate programs identified put the onus of interdisciplinarity and transdisciplinarity on the student. That is, the student is held responsible for synthesizing the methods and skills of each discipline, understanding and disambiguating potentially overlapping lexicons, and creating a space for new methods to emerge. Beyond this, we failed to identify any courses designed for the undergraduate level to encourage and develop skills in KTT and KM, skills necessary to work in a truly interdisciplinary or transdisciplinary setting.

\section{Graduate programs}

As is the case with undergraduate programs and certificates, interdisciplinary programs directed at graduate students were found within and between the 
domains of physical and engineering sciences, arts, social sciences and humanities, and health sciences. Again, there were no programs identified that selflabeled as transdisciplinary.

In most cases, students enrolled in interdisciplinary graduate programs are left to their own devices to develop a choose-your-own-adventure degree. The students necessarily register their degree within a participating department but take courses offered in several. While this provides the student with flexibility to explore multiple disciplines through discipline-specific courses, it means that student learning takes place in a siloed context. As such, much of the interdisciplinarity (or transdisciplinarity) of the graduate degree occurs outside of a formal classroom setting, most likely appearing as part of the student's specific research, or present during graduate committee meetings when multiple disciplines are present in the form of advisors and other domain experts. There does not appear to be many tools provided to the student that would have them purposefully working with and learning from other disciplines to solve a problem, and no spaces for truly interdisciplinary or transdisciplinary solutions to emerge. And again, the onus is generally upon the student to make meaning of interdisciplinarity.

Beyond a lack of tools provided for interdisciplinary and transdisciplinary work, few programs were found to offer specific graduate courses in KTT or KM. There are several notable exceptions that have been highlighted by KTClearinghouse.ca, a CIHR funded online KTT repository jointly managed by the University of Toronto and St. Michael's Hospital. These include courses in knowledge translation (or with major learning outcomes that address KTT and KM) for graduate degrees primarily in the health sciences offered at the University of Alberta, the University of Calgary, McMaster University, University of Ottawa, University of Toronto, Western University, and Laval.

\section{Institutions, faculties, and other resources}

To help manage or facilitate interdisciplinary programs and research, many universities have created interdisciplinary institutions, faculties, or some form of governing bodies. Examples include (but are not limited to) Athabasca University's Centre for Interdisciplinary Studies in the Faculty of Humanities and Social Sciences (http://cis.athabasca u.ca/), Carleton's Institute of Interdisciplinary Studies (http://carleton.ca/iis/), the School of Interdisciplinary Science at McMaster University (https://www.science.mcmaster.ca/sis/), the Centennial Centre for Interdisciplinary Science at the University of Alberta (https://www.ualberta.ca/scienc e/about-us/facilities), the Centre for Interdisciplinary Research in the Mathematical and Computational Sciences at Simon Fraser University (http://www.irmacs.sfu.ca/), and the Transdisciplinary Research Hub at Brock University (https://brocku.ca/transdisciplinarity/). The role of such institutions, faculties, and governing bodies is to provide students and faculty with open spaces that facilitate cross-disciplinary research collaborations, or to provide students with a specific set of program requirements, and program related information. Here we highlight a few examples from a subset of Canadian universities.

Within the University of Ottawa's Faculty of Education exists the research group known as the Multiplicities and Transdisciplinary Experimentations Research Unit. With a focus on developing education and educational practices, the unit tries to break down assumptions about disciplinary boundaries through various research projects (Faculty of Education, University of Ottawa, n.d.). As a result, the publications and presentations listed by the group span a wide variety of topics within the arts and social sciences, but all with a focus on education (Bangou $\&$ Masny, 2014). Those involved in the research unit are primarily professors and graduate students at the masters or doctorate levels interested in researching transdisciplinary education (Bangou \& Masny, 2014). 
To encourage transdisciplinary work, Brock University has also created a hub dedicated to transdisciplinary research (https://brocku.ca/transdis ciplinarity/). Of the programs reviewed in this study, Brock University's transdisciplinary initiative appears to be the largest and widest reaching in terms of the breadth of knowledge and disciplines being combined. Five different hubs exist at the university: The Advanced Biomanufacturing Centre, The BrockNiagara Centre for Health and Well-being, The Environmental Sustainability Research Centre, The Centre for Lifespan Development Research, and The Social Justice Research Institute (Brock University, n.d.). As their names suggest, each of these hubs has a different focus and each incorporates different disciplines to achieve research goals. These hubs primarily involve faculty and graduate students ${ }^{4}$.

Mount Royal University has incorporated transdisciplinary work into their Faculty of Arts through their Centre for Community-Based Disaster Research (Mount Royal University, 2015). This program seeks to benefit from professionals from an array of disciplines in the fight to create and implement plans that best assist communities when they experience various disasters, and investigate the consequences of such disasters on victims (Mount Royal University, 2015). The centre involves members from across the university, including students, researchers, community members, and other stakeholders (Mount Royal University, 2015).

McMaster University has created an interdisciplinary school, designed to integrate engineering and technology, as well as to establish some scaffolding between Masters students and senior undergraduates (Walter Booth School of Engineering Practice and Technology, 2016). Undergraduates are able to take courses that can be put towards graduate studies later on while getting exposed to a higher level of learning through collaboration with graduate students on real-world challenges. Graduate students take on the position of mentors, with the ability to promote deeper analytical thinking in their mentees by challenging them to consider other points of view.
During the experience, all students are able to connect to members of the community and industry, adding a valuable component to this initiative.

Other universities have identified the potential effectiveness of transdisciplinary work in the healthcare domain. The programs range from those spanning multiple universities, to those specific to a singular post-secondary educational institution, such as the CIHR funded transdisciplinary research program for health care, or the Terry Fox Transdisciplinary Training Program, both located at Queen's University (Queen's University, n.d.).

The University of Ottawa has explored a transdisciplinary approach to educating undergraduate students in the health sciences through their Transdisciplinary Community Health Project (University of Ottawa, Faculty of Health Sciences, 2010; University of Ottawa, 2012). As part of this initiative, students spend time exploring modules related to community-engaged scholarship, social justice, etc., and then work with a community partner on a health-related project within the community (University of Ottawa, 2012). One of the goals listed by the project is to allow students to gain transdisciplinary skills through work with professionals from various disciplines (University of Ottawa, 2012).

The Transdisciplinary Understanding and Training on Research-Primary Health Care (TUTOR-PHC) is a training program that was funded by the CIHR and involved several universities across the country (Welcome to TUTOR-PHC, n.d.). Participants of the program included students completing graduate degrees and post-doctorates, or industry professionals (Overview and Justification, n.d.). The TUTOR-PHC program differs significantly from most other transdisciplinary programs reviewed in that it was not specific to a single university, and was focused entirely on improving healthcare by educating transdisciplinary thinking healthcare professionals (Overview and Justification, n.d.). A similar initiative known as Tomorrow's Research Cardiovascular Health

\footnotetext{
${ }^{4}$ A detailed reading of the various 'Research Units' listed on the "Transdisciplinarity at Brock" homepage describes which disciplines are involved in which units. Availability to faculty and graduates was determined by further reading of webpages on each site.
} 
Professionals (TORCH) is a joint program between the University of Alberta and the University of Calgary that seeks to educate researchers in the health sciences from a transdisciplinary mindset to improve research quality (Centre for Health Evidence, 2012).

Beyond the institutions and research hubs described previously, other institutions have identified the importance of interdisciplinary and transdisciplinary research and education through various other means. For example, the Provost of Ryerson has created an Interdisciplinary Teaching Award to support innovative and interdisciplinary teaching on campus. The award "recognizes a Ryerson educator or a group of educators who have made contributions to advancing teaching and learning at Ryerson with a particular focus on Interdisciplinary teaching and on students' Interdisciplinary learning and who have an outstanding teaching record" (Ryerson University, n.d., para. 1). This is the only teaching award that our research identified with a specific focus on interdisciplinary or transdisciplinary education. Further, York University has recently identified a call for a Tier One Canadian Research Chair in Global Governance and Social Innovation within their School of Health Policy and Management. The specific mandate of the Chair is to create a Social Innovation Think Tank that will act as a hub for transdisciplinary research, training, and mentorship (York University, 2016). Finally, several universities including Concordia and the University of Quebec at Montreal have made interdisciplinary and transdisciplinary education and research an integral part of their most recent (or upcoming) strategic mandates (Concordia University, n.d.; University of Quebec at Montreal, 2009).

\section{Trends in Canadian University Transdisciplinary Projects}

The review of interdisciplinary and transdisciplinary Tri-Council funding and university programs across Canada has identified several key observations and trends that are relevant to developing transdisciplinary opportunities within the setting of higher education. We adopted the rating scale by Jacobs et al. (2014), classifying the level of transdisciplinarity as either low (having two distinct disciplines), medium (having three distinct disciplines) or high (having four or more distinct disciplines). An example of a distinct discipline would be biology and geography, but not environmental versus electrical engineering. All findings provide some insight regarding potential mechanisms for facilitating a space for knowledge builders to come together in a transdisciplinary setting. Specifically:

1. Interdisciplinary and transdisciplinary research has been readily accepted by the health sciences earlier and more often than any other discipline. This is exemplified by the array of projects from Brock University, the University of Ottawa, the University of Alberta, the University of Calgary, and all those universities that have been part of the TUTOR-PHC program (Armstrong et al., 2004; Brock University, n.d.; University of Ottawa, Faculty of Health Sciences, 2010; University of Ottawa, 2012; Welcome to TUTOR-PHC, n.d.).

2. Regardless, both NSERC and SSHRC have increased the funding awarded to research programs that have self-identified as interdisciplinary or transdisciplinary in nature. Presumably, this suggests that the number of graduate student research opportunities that span or transcend disciplines is increasing as well.

3. Total annual funding awarded by NSERC to self-identified interdisciplinary and transdisciplinary research programs is now on par with CIHR, while total annual SSHRC funding awarded to such programs currently sits at approximately $25 \%$ of NSERC awards. Moreover, NSERC has increased the total annual awards for transdisciplinary research (from 0.03 to $0.17 \%$ of its total budget), while SSHRC has remained stable, and CIHR has decreased.

4. Funding for transdisciplinary specific research programs is awarded primarily from CIHR. It provides more than 4 times the 
funding than NSERC awards and almost 15 times the funding awarded by SSHRC.

5. Interestingly, despite a significant number of research hubs, institutions, and programs across the country which focus on transdisciplinary health care education, the total funding from CIHR for transdisciplinary programs has decreased. In fact, CIHR funding for transdisciplinary research programs has dropped from 1.13 to $0.90 \%$ of their total yearly funding awarded.

6. Regardless of the funding amounts awarded by Tri-Council agencies to self-identified transdisciplinary programs, there were no undergraduate or graduate degree programs identified as transdisciplinary in nature.

7. Of the interdisciplinary undergraduate and graduate degree programs identified, all were relatively siloed. That is, students enrolled in the programs were required to complete courses spanning multiple disciplines (becoming mini-masters of multiple domains), but there was no evidence that they were provided tools to transcend the disciplines. In essence, students, while able to customize their studies based on individual preferences, did not have an available course designed specifically to aid in their ability to integrate knowledge beyond disciplinary boundaries.

8. The programs and faculties identified as interdisciplinary or transdisciplinary in nature were limited to a few disciplines. In numerous cases, the disciplines fell under the umbrella of a single domain of work (e.g., physical and engineering sciences, arts, and humanities). That is, students choosing to study under the interdisciplinary or transdisciplinary banner were typically exposed to similar disciplines (refer to Appendix A).

9. There were few courses dedicated to teaching undergraduate or graduate students the skills (e.g. KTT) necessary for truly transdisciplinary work to occur. Further, students participating in interdisciplinary or transdisciplinary programs were provided experiential learning opportunities (such as a community-engaged scholarship), but this was not the norm.

Despite Tri-Council funding that supports or requires interdisciplinary and transdisciplinary research (e.g. NSERC's CREATE grant), Canadian universities lack undergraduate or graduate programs that successfully balance research goals with the education of students. Institutions typically have implemented a research hub model by combining two or more disciplines focused on the study of a particular issue. Many of these hubs, however, were created for the purpose of fostering an interdisciplinary or transdisciplinary research approach, but they were not able to or did not consider integrating an educational framework. That is, hubs have been created to facilitate graduate student and faculty research, but specific courses that foster skills required for interdisciplinary and transdisciplinary thinking at either the undergraduate or graduate level were few and far between. In essence, new silos of transdisciplinary research have been erected but with little to no access for undergraduate students. Even in cases where undergraduate or graduate programs for interdisciplinary or transdisciplinary work exist, students are faced with a lack of tools that foster interdisciplinary or transdisciplinary thinking.

Ultimately it appears that Canadian universities have attempted to embed interdisciplinary and transdisciplinary research and education using a trickle-down approach that does not disrupt the traditional academic framework. Funding has supported the development of hubs, and some degree programs, however, formal interdisciplinary and transdisciplinary training is lacking.

With these observations in mind, there is clearly a need to develop a framework that supports and encourages transdisciplinary skills.

\section{Proposed Framework}

These initiatives have paved the way for new and increasingly transdisciplinary programs that include both graduate and undergraduate students. But is 
offering a truly transdisciplinary learning and research opportunity to undergraduate students even possible within the current academic framework? Typically, within Canadian post-secondary institutions, degreegranting programs are run by discipline-specific departments within a larger unit (i.e. college or faculty). These departments generally offer a few senior undergraduate courses with built-in flexibility and very few restrictions to allow students to conduct research or write a literature review on a topic of personal interest. These courses normally have a designated faculty coordinator, with each student also having a faculty advisor. Therefore, the faculty to student ratio is slightly more than $1: 1$, depending on the number of students enrolled in the course. Undergraduate students usually also have access to a variety of institution-level courses with similar flexibility but these are taken as electives rather than credit towards the degree major.

Creating new courses is an arduous task that often requires several years of consultation and administrative paperwork. Creating a course that would be recognized by all departments as credit towards a student's degree major would perhaps be impossible. Therefore, we sought to create a pilot project that could 1) be used by students towards their degree major and 2) did not require the creation of a new course.

The pilot project, called Ideas Congress (ICON), is being developed and practiced at the University of Guelph. ICON is available to all senior undergraduate students with access to an independent study course through their degree major. The program uses the existing course codes for the independent study projects such that no new courses or changes to graduation requirements were necessary. Therefore, all students enrolled in their department's independent study course are given a choice: follow the traditional model with a faculty supervisor to work on a research project or literature review, or join ICON to work within a transdisciplinary learning environment on a collaborative project.

In this way, we attract students from many disciplines who learn about the principles of KTT and work together on a project developed in partnership between faculty at the University and a different community partner each semester. Students are able to earn course credit towards their degree major and fulfill those requirements set out by their individual courses while working on a real-world problem that they will solve in a transdisciplinary learning environment. The community partner benefits from interactions with the students, tapping into a new source of innovative and creative solutions. By the end of the program, the challenge is solved, often with several options from which to choose. Finally, this type of program is beneficial to faculty and administrators. The format of the course allows for a greater ratio of students to advisors (First year: 1:12, second year: $1: 20$ ), furthering access by students to these often-limited enrollment experiences.

ICON has three major goals:

1. To encourage and foster transdisciplinary learning, research, and appreciation by bringing together students with skills from different departments and challenging them with real-world problems from the local, regional, and/or global community.

2. To strengthen discipline-specific knowledge learned in class by providing students with the appropriate platform and tools to act as a teacher to their fellow students.

3. To enhance discipline specific knowledge learned in class by requiring students to work directly with community partners, thereby exposing students to outside-the-classroom education and relevant discipline knowledge application.

Following two offerings of ICON, we have identified several areas for improving our model. While our model of tapping into all of the senior undergraduate courses serves our purpose for creating a transdisciplinary learning environment for students, it requires that we meet the individual and specific assessment requirements for each of them. This means that students in ICON are evaluated in different ways and often with different weightings for each assignment. We believe that our model as it is currently will allow us to continue to offer ICON and to conduct program assessments while we work towards establishing a university-wide ICON course that will be recognized by all degree majors. 


\section{Conclusions}

This article has provided an overview of the state of interdisciplinary and transdisciplinary research and education opportunities for students in Canada. While there have been some interdisciplinary efforts in schools across the country, the review suggests that transdisciplinary education programs are not widespread or intensive. Where interdisciplinarity is identified, students are often forced to integrate knowledge from siloed courses without specific training in KTT or KM. To address these shortcomings, we have presented a novel framework on which to develop a classroom at the undergraduate level that specializes in KTT, KM, and transdisciplinarity.

\section{References}

Aboelela, S. W., Larson, E., Bakken, S., Carrasquillo, O., Formicola, A., Glied, S. A., Haas, J., \& Gebbie, K. M. (2007). Defining interdisciplinary research: Conclusions from a critical review of the literature. Health Services Research, 42(1 Pt 1), 329-46. VIEW ITEM

Abramo, G., D’Angelo, C. A., \& Caprasecca, A. (2009). Allocative efficiency in public research funding: Can bibliometrics help? Research Policy, 38(1), 206-215. VIEW ITEM

Armstrong, P. W., Ezekowitz, C., Michelakis, E., Anderson, T., Archer, S., Ghali, W., ... Sheldon, R. (2004). Innovative strategic Canadian research training from TomorrOw's Research Cardiovascular Health Care Professionals (TORCH). Clinical and Investigative Medicine, 27(1): 33-41. VIEW ITEM

Bangou, F., \& Masny, D. (2014). Annual Newsletter: Spring 2014. Multiplicities \& Transdisciplinary Experimentations, 9(1), 1-13. VIEW ITEM
Bank of Canada. (n.d.). Inflation Calculator. VIEW ITEM

Brock University. (n.d.). Transdisciplinarity at Brock. VIEW ITEM

Choi, B. C. K., \& Pak, A. W. P. (2006). Multidisciplinarity, interdisciplinarity and transdisciplinarity in health research, services, education and policy: 1. Definitions, objectives and evidence of effectiveness. Clinical and Investigative Medicine, 29(6): 351364. VIEW ITEM

Committee on Facilitating Interdisciplinary Research, National Academy of Sciences, National Academy of Engineering, Institute of Medicine. (2005). Facilitating Interdisciplinary Research. VIEW ITEM

Concordia University. (n.d.). Strategic directions. VIEW ITEM

Faculty of Education, University of Ottawa. (n.d.). About: Aims of the research unit: to read the world in multiple ways [website description]. VIEW ITEM

Grey, M., \& Connolly, C. A. (2008). "Coming together, keeping together, working together": Interdisciplinary to transdisciplinary research and nursing. Nursing Outlook, 56(3), 102-7. VIEW ITEM

Hagoel, L. \& Kalekin-Fishman, D. (2002). Crossing borders: Toward a trans-disciplinary scientific identity. Studies in Higher Education, 27(3), 297-308. VIEW ITEM

Hango, D. (2013, December). Gender differences in science, technology, engineering, mathematics and computer science (STEM) programs at university. Insights on Canadian Society: Statistics Canada. 75-006-X, 1-11. VIEW ITEM 
Hubball, H., Clarke, A. and Poole, G. (2010). Tenyear reflection on mentoring SoTL research in a research-intensive university. International Journal for Academic Development, 15(2): 117 129. VIEW ITEM

Jacobs, S. R., Nicol, E. C. \& Helms, M. E. (2014). Where are we now and where are we going? The BioM Innovation Database. Journal of Mechanical Design. 136(11), 1-10. VIEW ITEM

Kolb, A. Y. \& Kolb, D. A. (2005). Learning styles and learning spaces: Enhancing experiential learning in higher education. Academy of Management Learning \& Education 4(2), 193212. VIEW ITEM

McGregor, S. L. T. \& Donnelly, G. (2014). Transleadership for transdisciplinary initiatives. World Future, 70(3-4), 164-185. VIEW ITEM

Mount Royal University. (2015) A new centre and award winning research. VIEW ITEM

Overview and Justification. (n.d.). Western University, TUTOR-PHC. VIEW ITEM

Pohl, C., \& Hadorn, G. H. (2007). Principles for designing transdisciplinary research (A. B. Zimmermann, Trans.). Munich: Oekom Verlag GmbH.

Queen's University. (n.d.). Terry Fox Foundation training program in transdisciplinary cancer research in partnership with CIHR. VIEW ITEM

Rosenfield, P. L. (1992). The potential of transdisciplinary research for sustaining and extending linkages between the health and social sciences. Social Science \& Medicine, 35(11), 1343-57. VIEW ITEM

Roux, D. J., Stirzaker, R. J., Breen, C. M., Lefroy, E. C., \& Cresswell, H. P. (2010). Framework for participative reflection on the accomplishment of transdisciplinary research programs. Environmental Science and Policy, 13(8), 733741. VIEW ITEM

Ryerson University. (n.d.). Provost's Interdisciplinary Teaching Award [website description]. VIEW ITEM

Schary, D. P. \& Cardinal, B. J. (2015). Interdisciplinary research and reaching in kinesiology: Continuing the conversation. Quest, 67(2): 173-184. VIEW ITEM

Schmitt, O. (1960). Where are we now and where are we going? In J. C. Robinette (Ed.), Bionics Symposium: Living Prototypes - The Key to New Technology. Wright-Patterson Air Force Base, Ohio: Wright Air Development Division Technical Report.

Sengupta, I. N. (1985). Bibliometrics: A bird's eye view. IASLIC Bulletin 30(4), 167-174.

Singh, J., Illes, J., Lazzeroni, L., \& Hallmayer, J. (2009). Trends in US autism research funding. Journal of Autism Developmental Disorders 39(5), 788-795. VIEW ITEM

Statistics Canada. (2016). Table 358-0164: Federal extramural expenditures on science and technology performing, by performing sector and major departments and agencies. VIEW ITEM

Stauffer, J. (2015, Fall). Changing the face of STEM education: Balancing the scales in science, technology, engineering and math. University of Waterloo Magazine. VIEW ITEM

Tourse, R. W. C., Mooney, J. F., ShindulRothschild, J., Prince, J., Pulcini, J. A., Platt, S. \& Savransky, H. (2008). The university/community partnership: Transdisciplinary course development. Journal of Interprofessional Care, 22(5), 461-474. VIEW ITEM 
University of Ottawa. (2012). The Faculty of Health Sciences congratulates the community involvement of its students. VIEW ITEM

University of Ottawa, Faculty of Health Sciences. (2010). Transdisciplinary community bealth engagement: Request for registration. VIEW ITEM

University of Quebec at Montreal. (2009). UQAMStrategic Research Plan 2009-2014. VIEW ITEM

Walter Booth School of Engineering Practice and Technology. (2016). Faculty of Engineering introduces the 'new' Walter G. Booth School of Engineering and Technology. VIEW ITEM

Welcome to TUTOR-PHC. (n.d.). Western University, TUTOR-PHC. VIEW ITEM

Wilcox, B., \& Kueffer, C. (2008). Transdisciplinarity in ecohealth: Status and future prospects. EcoHealth, 5(1), 1-3. VIEW ITEM

York University (2016). Canada Research Chair (Tier 1) in Global Governance and Social Innovation: School of Health Policy and Management, Faculty of Health. VIEW ITEM

\section{Acknowledgements}

The authors would like to thank the Office of the Provost and the McConnell Foundation for supporting our research and teaching scholarship efforts.

\section{Biographies}

Daniel Gillis, $\mathrm{PhD}$, is an Associate Professor in the School of Computer Science at the University of Guelph. He is also the director of The Physical Science and Engineering Education Research Centre (PSEER). His research interests span statistics, computer science, biology, pedagogy and community-engaged scholarship.

Jessica Nelson was an undergraduate student conducting her research under the supervision of Shoshanah Jacobs and Daniel Gillis. She graduated with a double major in Biology and English.

Brianna Driscoll was an undergraduate research assistant working under the supervision of Daniel Gillis. She graduated with a degree in English and Anthropology.

Kelly Hodgins is a program coordinator for the Feeding 9 Billion Challenge in the Department of Geography at the University of Guelph.

Evan Fraser, $\mathrm{PhD}$, is a Professor in the Department of Geography and the Director of the Arrell Food Institute at the University of Guelph. His research interests include food security, land use, and global environmental/economic change.

Shoshanah Jacobs, $\mathrm{PhD}$, is an Assistant Professor in the Department of Integrative Biology and a member of the College of Biological Sciences Office of Educational Scholarship and Practice at the University of Guelph. Her research interests span Arctic seabird foraging ecology, knowledge translation and transfer, and science education. 


\section{Appendix A}

Research of Transdisciplinary Programs Offered in Universities Across Canada. Programs were evaluated on a number of criterion, as indicated below. The rating component refers to the level of transdisciplinarity as adopted by Jacobs et al. (2014). Education level refers to who was able to access these programs, whether undergraduates (UG), graduates $(G)$ or postdoctoral $(P D)$ students. Programs were given a rating of yes $(Y)$ or no $(N)$ for community partner and knowledge translation and transfer (KTT) criterion based on direct reference to partners or KTT/knowledge mobilization efforts, respectively.

\begin{tabular}{lcccccc}
\hline Program & $\begin{array}{c}\text { Research } \\
\text { Component }\end{array}$ & $\begin{array}{c}\text { Education } \\
\text { level }\end{array}$ & Rating & $\begin{array}{c}\text { Major Fields of } \\
\text { Study }\end{array}$ & $\begin{array}{c}\text { Community } \\
\text { Partner^ }\end{array}$ & $\begin{array}{c}\text { KTT } \\
\text { Component }\end{array}$ \\
\hline Brock University: Transdisciplinary Research Hubs & & &
\end{tabular}

Advanced

Biomanufacturing

Centre

$\sqrt{ }$

G

Low

STEM

Y

$\mathrm{N}$

Brock-Niagara Centre

for Healthy and Well-

Being

$\sqrt{ }$

G

Low

STEM

Y

Y

Environmental

Sustainability Research

Centre (ESRC)

$\sqrt{ }$

Med -

Centre for Lifespan

Development Research

$\sqrt{ }$

G

High

STEM

Y

Y

Centre for Digital

Humanities

$\sqrt{ }$

UG

Med

STEM

Y

$\mathrm{N}$

Cool Climate Oenology

Med -

and Viticulture Institute (CCOVI)

$\sqrt{ } \quad \mathrm{UG}+\mathrm{G} \quad \mathrm{Med}$

STEM +

SOCIAL

SCIENCES

Y

N

SOCIAL

Posthumanism Research

Institute

$\sqrt{ }$

G

SCIENCES \&

Social Justice Research

Institute

$\sqrt{ } \quad \mathrm{UG}+\mathrm{G}$

Med -

High

STEM

Y

$\mathrm{N}$ 


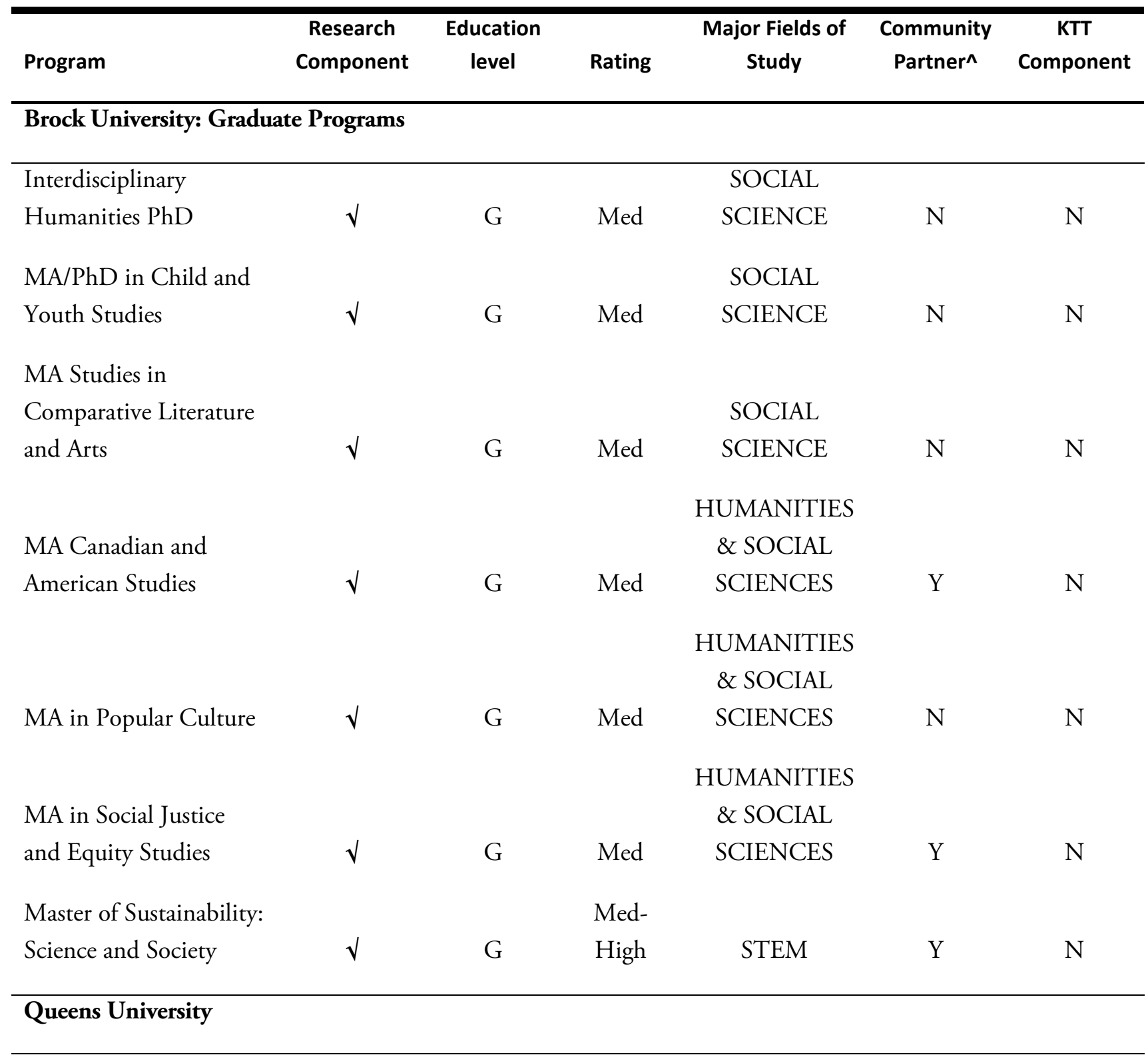

Terry Fox Foundation

Training Program in

Transdisciplinary

Low -

$\begin{array}{lllllllll}\text { Cancer Research } & \sqrt{ } & \mathrm{G} & \text { Med } & \text { STEM } & \mathrm{N} & \mathrm{N}\end{array}$

\section{Mount Royal University}

Community Based

Low -

Disaster Research

$\sqrt{ } \quad$ G $\quad$ Med

STEM + ARTS

Y

Y

\section{University of Ottawa}




\begin{tabular}{lcccccc}
\hline Program & $\begin{array}{c}\text { Research } \\
\text { Component }\end{array}$ & $\begin{array}{c}\text { Education } \\
\text { level }\end{array}$ & Rating & $\begin{array}{c}\text { Major Fields of } \\
\text { Study }\end{array}$ & $\begin{array}{c}\text { Community } \\
\text { Partner^ }\end{array}$ & $\begin{array}{c}\text { KTT } \\
\text { Component }\end{array}$ \\
\hline $\begin{array}{l}\text { Transdisciplinary } \\
\text { Community Health } \\
\text { Project }\end{array}$ & $\mathrm{x}$ & $\mathrm{UG}$ & Low & STEM & $\mathrm{Y}$ & $\mathrm{Y}$ \\
$\begin{array}{l}\text { Interdisciplinary School } \\
\text { of Health Sciences }\end{array}$ & $\sqrt{ }$ & $\mathrm{UG}+\mathrm{G}$ & High & SCIENCES & $\mathrm{N}$ & $\mathrm{N}$ \\
$\begin{array}{l}\text { Multiplicities and } \\
\text { transdisciplinary } \\
\text { experimentations } \\
\text { (MTE) }\end{array}$ & & & STEM + & & \\
& & & & & & \\
\hline
\end{tabular}

\section{University of British Columbia}

Transdisciplinary

understanding and

training of research

Low -

$\begin{array}{lllllll}(\text { TUTOR-PHC) } & \sqrt{ } & \mathrm{G}+\mathrm{PD} & \mathrm{Med} & \text { STEM } & \mathrm{Y} & \mathrm{N}\end{array}$

\section{University of Western}

\begin{tabular}{|c|c|c|c|c|c|c|}
\hline TUTOR-PHC & $\sqrt{ }$ & $G+P D$ & $\begin{array}{l}\text { Low - } \\
\text { Med }\end{array}$ & STEM & $\mathrm{Y}$ & $\mathrm{N}$ \\
\hline \multicolumn{7}{|l|}{ Robarts Research } \\
\hline \multicolumn{7}{|l|}{ Institute: } \\
\hline \multicolumn{7}{|l|}{ Transdisciplinary } \\
\hline training program & $\sqrt{ }$ & G & Med & STEM & $\mathrm{N}$ & $\mathrm{N}$ \\
\hline \multicolumn{7}{|l|}{ McGill University } \\
\hline Schulich School of & & & Med - & & & \\
\hline Music & $\sqrt{ }$ & G & High & STEM + ARTS & $\mathrm{N}$ & $\mathrm{N}$ \\
\hline \multicolumn{7}{|c|}{ Concordia University in Montreal } \\
\hline \multicolumn{7}{|l|}{ Major Research Clusters } \\
\hline in their Strategic & & & Med - & & & \\
\hline research plan 2013-18 & $\sqrt{ }$ & $G+P D$ & High & STEM + ARTS & $\mathrm{Y}$ & $\mathrm{Y}$ \\
\hline
\end{tabular}

\section{Simon Fraser University}




\begin{tabular}{|c|c|c|c|c|c|c|}
\hline Program & $\begin{array}{c}\text { Research } \\
\text { Component }\end{array}$ & $\begin{array}{c}\text { Education } \\
\text { level }\end{array}$ & Rating & $\begin{array}{l}\text { Major Fields of } \\
\text { Study }\end{array}$ & $\begin{array}{l}\text { Community } \\
\text { Partner^ }^{\wedge}\end{array}$ & $\begin{array}{c}\text { KTT } \\
\text { Component }\end{array}$ \\
\hline \multicolumn{7}{|l|}{ TransNet $(2005$} \\
\hline Conference) & $\sqrt{ }$ & G & Med & STEM + ARTS & $\mathrm{Y}$ & $\mathrm{N}$ \\
\hline \multicolumn{7}{|l|}{ Transdisciplinary } \\
\hline \multicolumn{7}{|l|}{ Research Centre for } \\
\hline \multicolumn{7}{|l|}{ Performance and } \\
\hline Technology & & & Med- & & & \\
\hline (TRansCPT) & $\sqrt{ }$ & G & High & STEM + ARTS & $\mathrm{Y}$ & $\mathrm{N}$ \\
\hline \multicolumn{7}{|c|}{ Canadian Institutes of Health Research (CIHR) } \\
\hline \multicolumn{7}{|l|}{ Strategic Training } \\
\hline \multicolumn{7}{|l|}{ Initiative in Health } \\
\hline \multicolumn{7}{|l|}{ Research (STIHR): } \\
\hline \multicolumn{7}{|l|}{ Programs at 15} \\
\hline Canadian Universities & & & Low - & & & Program \\
\hline Funded & $\sqrt{ }$ & $\mathrm{G}^{*}$ & High & STEM & Y & specific \\
\hline \multicolumn{7}{|l|}{ McMaster } \\
\hline \multicolumn{7}{|l|}{ wBooth School of } \\
\hline $\begin{array}{l}\text { Engineering Practice } \\
\text { and Technology }\end{array}$ & $\sqrt{ }$ & $\mathrm{UG}+\mathrm{G}$ & Low-Med & STEM & $\mathrm{Y}$ & $\mathrm{Y}$ \\
\hline
\end{tabular}

